\section{Effect of patterns of shock and nonshock training trials on response alternation and extinction in escape training*}

\author{
JOSEPH J. FRANCHINA \\ Virginia Polytechnic Institute and State University, Blacksburg, Va. 24061 \\ and \\ C. R. SNYDER \\ Vanderbilt University, Nashville, Tenn. 37203
}

Escape behavior was trained under $100 \%$ shock schedules or $50 \%$ schedules of shock and nonshock presented in single-alternation, random, or counterbalanced sequences. Terminal acquisition was highest for $100 \%$ shock. For $50 \%$ schedules nonshock trial performance was reliably slower for alternation than for random or counterbalanced sequences; shock trial performance showed no reliable pattern effects. In extinction, performance on early trials decreased reliably for all groups except the $50 \%$ alternation group.

Nonspatial alternation of fast and slow responding based on alternating reward and nonreward has been well documented for appetitive learning (e.g., Bloom \& Capaldi, 1961). The present experiment investigated whether nonspatial alternation would occur in aversive conditioning (escape training), based on alternating the presence and absence of a primary motivator electric shock. Accordingly, escape behavior was studied under single-alternation (SA), random (R), and counterbalanced (C) $50 \%$ schedules of shock and nonshock. Evidence for alternation was SA group's responding faster on shock and slower on nonshock trials than $R$ or $C$ groups. $A$ between-groups evaluation of alternation was used instead of the more usual within-S approach of appetitive studies (e.g., Bloom \& Capaldi, 1961) to avoid confounding stimulus-intensity effects with sequential trials effects of shock and nonshock presentations. Nonshock trial performance has been frequently reported (e.g., Franchina, 1969) as reliably slower than shock trial performance. Thus, nonspatial atlernation, demonstrated within $\mathrm{S}$ under SA, might be attributed to differences in relative stimulus intensity between shock and nonshock trials rather than to $S A$ sequential effects. Between-groups comparison of SA, R, and $\mathrm{C}$ on shock and on nonshock trials separately provided that stimulus intensity was held constant while the effects of shock-nonshock sequences were evaluated. APPARATUS

The apparatus was described in detail by Franchina (1968). Briefly, a white startbox was separated from a black safebox by a guillotine door and a hurdle. The startbox

*These data were collected at Southern Methodist University. floor was of steel rods wired to a constant-voltage source (dc) for $50-\mathrm{V}$ shock. The safebox floor was Masonite and could be depressed by S's weight to act as a switch. Illumination in each box was constant at $7 \mathrm{fc}$.

\section{SUBJECTS, DESIGN AND PROCEDURES}

Forty-eight naive female Holtzman albino rats, $100-110$ days old, received 2 days of exploration of the apparatus at 16 min per day. On Day 3 Ss were randomly and evenly assigned to 100 , 50SA, 50R, or 50C groups for 10 days of escape training at 16 trials/day. Group 100 had shock on all trials. The 50SA, 50R, and $50 \mathrm{C}$ groups had shock and nonshock trials intermixed on a $50 \%$ basis in alternation, random, and counterbalanced sequences, respectively. Each $50 \%$ group had the same equal number of daily shock and nonshock trials. For 50SA odd-numbered trials were nonshock, even-numbered were shock.

For a shock training trial $S$ was placed into the startbox and $10 \mathrm{sec}$ later the guillotine door was raised, simultaneously activating shock and a .01-sec unit timer. If $S$ jumped the hurdle, the safebox floor depressed, stopping the timer. Ten seconds later $S$ was removed to its home cage for a 90-sec ITI. If $S$ failed to jump the hurdle within $40 \mathrm{sec}$, the shock was kept on, $\mathrm{S}$ was removed from the startbox to the home cage, and a latency of $40 \mathrm{sec}$ was recorded. Nonshock trials followed these procedures, except that shock was omitted.

Extinction with nonshock began on the day after training ended. To minimize the possible decremental effects of a between-day shift from acquisition to extinction, Trials 1-4 on Extinction Day 1 were training trials administered to each group under its appropriate schedule.
Extinction trials comprised the last 12 trials of Day 1 and 16 trials/day for the next 3 days. These nonshock trials were conducted exactly as in training. All performance measures were converted to reciprocals of latency.

\section{RESULTS}

Training

Since the alternation data are of primary interest, the effect of training schedules on terminal performance will be mentioned briefly. Grand mean reciprocals of latency on the last training day (16 trials) were $2.00,1.77,1.72$, and 1.31 , for $100,50 \mathrm{R}$, $50 \mathrm{C}$, and 50SA, respectively. (Shock and nonshock data were combined for $50 \%$ groups.) Thus, terminal acquisition level increased with shock percentage (100 over all $50 \mathrm{~s}$ ) and with irregularity of $50 \%$ sequences. Analysis of variance over all groups yielded a reliable groups effect $(F=20.65, \mathrm{df}=3 / 44, p<.001)$. Scheffé comparisons yielded reliable differences between each pair of groups $(p<.005)$ except $50 R$ vs $50 \mathrm{C}(\mathrm{p}>.10)$.

Considering alternation, Fig. 1 presents the results of $50 \mathrm{C}, 50 \mathrm{R}$, and 50SA on shock and on nonshock trials. Evidence for alternation occurred on Nonshock Trial Blocks 21-40; 50SA was slower than 50R and $50 \mathrm{C}(\mathrm{F}=48.55, \mathrm{df}=2 / 33, \mathrm{p}<.001)$. Evidence for alternation failed to occur on shock trials; the groups performed similarly to each other. Analysis of variance over Trial Blocks $21-40$ yielded a groups $\mathrm{F}=1.33, \mathrm{df}=2 / 33, \mathrm{p}>.20$ ).

For interest, shock trial performance of $50 \%$ groups was compared with that of Group 100 over Blocks 21-40. No reliable groups effect occurred $(F=1.05)$, suggesting that interspersing nonshock among shock trials for $50 \%$ groups did not impair shock trial performance. Comparison of shock with nonshock trials for each $50 \%$ group reliably showed the frequently reported (e.g., Franchina, 1968, 1969) inferiority of nonshock performance (ps<.001).

\section{Extinction}

Figure 2 presents the performance of each group for the four training trials on Extinction Day 1 ( $\mathrm{ACQ}$, unattached points) and for all extinction trials. ACQ shows performance highly similar in appearance and statistical reliability to terminal acquisition levels reported earlier and, consequently, will be considered an index of such. For 50\% groups ACQ represents the combined data of shock and nonshock trials. Mean shock trial performance for $50 \mathrm{R}, 50 \mathrm{C}$, and 50SA on ACQ was $1.80,1.75$, and 1.70 , respectively, mean nonshock trial performance was $1.60,1.40$, and .68 , respectively. Comparison of $50 \%$ groups performance between $A C Q$ nonshock trials 


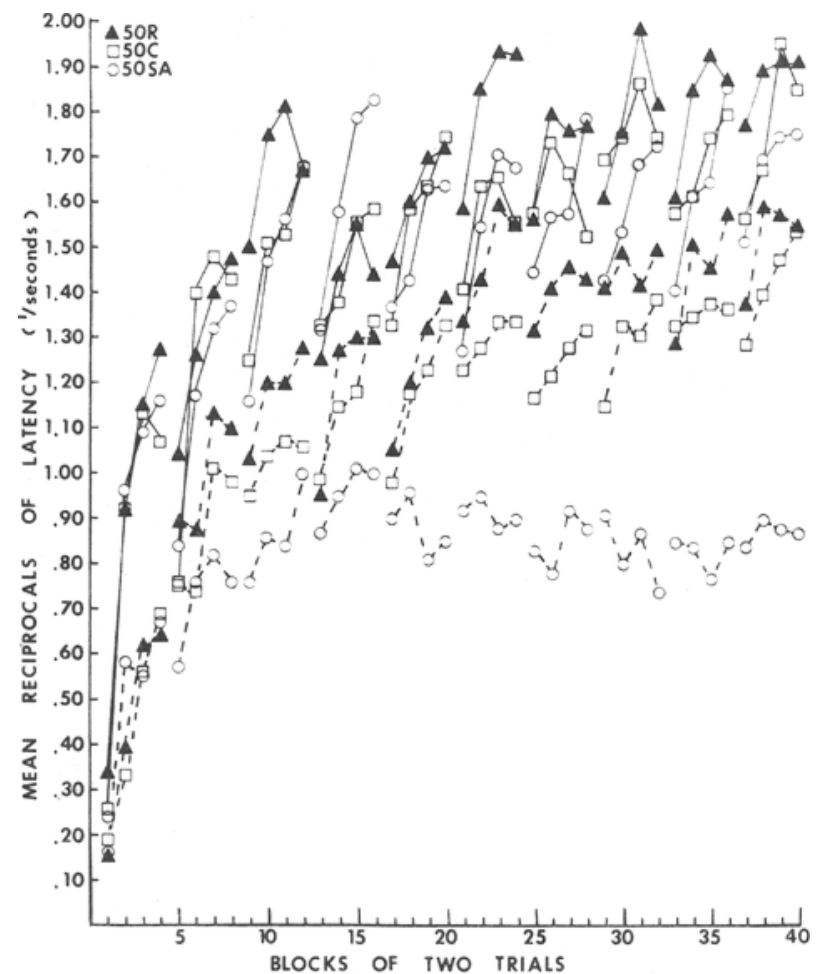

Fig. 1. Mean reciprocals of latency of hurdle jumping on corresponding blocks of two shock (solid line) and two nonshock (broken line) training trials for 50SA, 50R, and 50C groups.

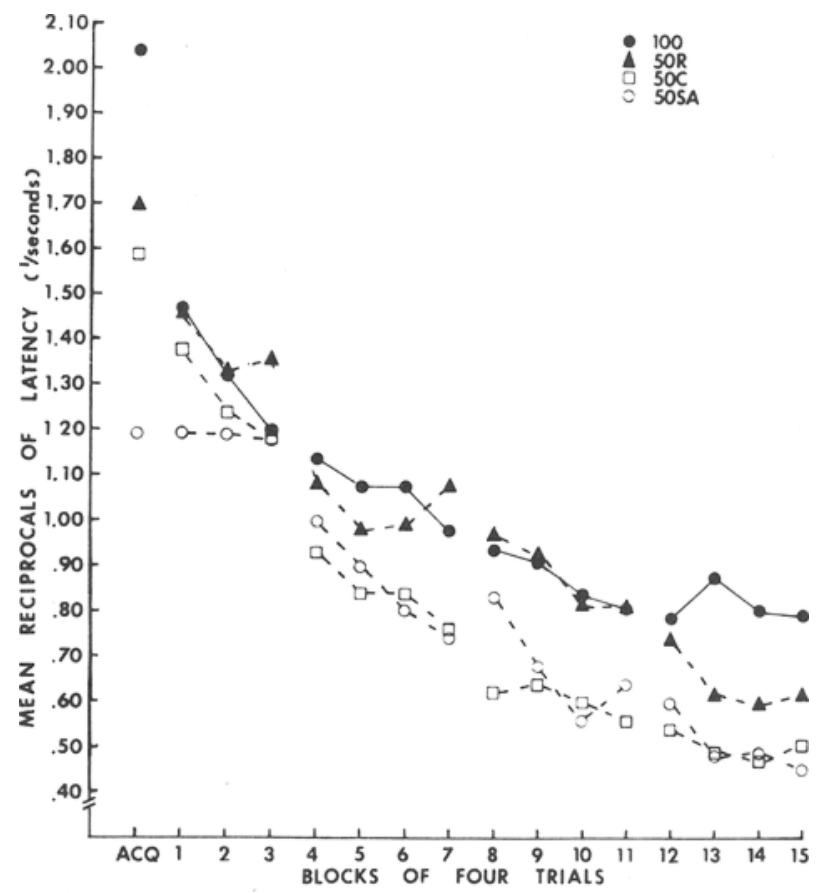

Fig. 2. Mean reciprocals of latency of hurdle jumping for each training condition on blocks of four trials for the training block of the first extinction day (ACQ) and for all extinction. and Trial Block 1 of extinction revealed a nonsignificant response decrement for $50 \mathrm{R}$ and $5 O C(\mathrm{t}<1)$ but a reliable increment in performance for 50SA, $t(11)=4.21$, $\mathrm{p}<.001$.

Analysis of variance over all Fig. 2 data (ACQ through Trial Block 15) yielded a reliable Groups by Trial Blocks interaction $(F=2.00, \mathrm{df}=45 / 660, \mathrm{p}<.01)$ explained as follows: On Extinction Day 1 (ACQ through Trial Block 3) performance decreased reliably for all groups except 50SA (trial blocks, $\mathrm{F}=16.80,8.50,6.00$, $1 ; \mathrm{df}=3 / 44 ; \mathrm{p}<.001,<.005,<.005$, $>.20$; for $100,50 \mathrm{R}, 50 \mathrm{C}$, and $50 \mathrm{SA}$, respectively). Analysis of variance over Trial Blocks 4-15 revealed a reliable performance decrement across all groups (trial blocks $F=74.00, \quad \mathrm{df}=11 / 484$, $\mathrm{p}<.001$ ), 100 and $50 \mathrm{R}$ being generally superior to $50 \mathrm{C}$ and $50 \mathrm{SA}$ (groups, $\mathrm{F}=3.56, \mathrm{df}=3 / 44, \mathrm{p}<.025$ ), with no reliable Groups by Trial Block interaction $(\mathrm{F}=1.25, \mathrm{df}=33 / 484, \mathrm{p}>.10)$.

$$
\text { DISCUSSION }
$$

Evidence for nonspatial alternation occurred reliably on nonshock but not on shock training trials. The former results suggested that alternating the presence and absence of a primary motivator, like electric shock, may yield sequential effects similar to those observed in appetitive learning (e.g., Bloom \& Capaldi, 1961).
However, unlike the appetitive data, the present results were not based on the alternation of reinforcement and nonreinforcement. Although such an alternation sequence was conceivable under escape procedures (reinforcement being shock offset, nonreinforcement being the lack of shock offset following instrumental behavior), preliminary data from this laboratory indicated the difficulty of maintaining hurdle jumping under these conditions. In this experiment then, hurdle jumping by $50 \%$ groups was continuously reinforced-on shock trials by shock offset and on nonshock trials by the reduction of fear conditioned to startbox cues by shock.

The present results for 50SA may have been due to the conditioning of slow and fast responding to the aftereffects stimuli of shock and nonshock trials. (Sources of these aftereffects may have been either shock and nonshock presentations or the presumed reinforcers, shock offset and fear reduction.) Under 50SA, shock trial aftereffects were presumably present and conditioned to escape behavior weakly elicited by nonshock on the next trial; conversely, nonshock trial aftereffects were presumably present and conditioned to vigorous escape responding elicited by shock on the next trial. Differential association of aftereffects and escape behavior was precluded for $50 \mathrm{R}$ and $50 \mathrm{C}$ by the irregularity of their shock-nonshock sequences. Thus, shock and nonshock aftereffects came to signal differential responding on the next trial for 50SA, thereby yielding slower nonshock and faster shock trial performance compared to $50 R$ and $50 \mathrm{C}$. Nonshock trial data conformed to these expectations but shock trial performance did not. This discrepancy may suggest either that on shock trials $50 . \mathrm{V}$ shock produced performance that obscured the influence of nonshock aftereffects for 50SA or that nonshock trial aftereffects were inefficient in signaling subsequent performance.

The latter alternative seems tenuous because nonshock trial aftereffects seemingly differentiated the groups in early extinction performance. Since nonshock trial aftereffects should be similar between training and extinction, behavior conditioned to these aftereffects in training should be elicited by them in extinction. For 50SA, then, escape behavior vigorously conditioned to the aftereffects of nonshock training trials should tend to be elicited by similar aftereffects on extinction trials. Thus the reliable increase in 50SA's performance between ACQ and Extinction Trial Block 1 was presumably due to facilitative effects of nonshock aftereffects present in extinction but not on ACQ and not for $50 \mathrm{R}$ and $50 \mathrm{C}$. 
Likewise, the reliable performance decrement on Extinction Day 1 for each group except 50SA presumably reflected the tendency of nonshock aftereffects to elicit vigorous escape behavior for 50SA. Unfortunately the effects of 50SA were transient. Later extinction data showed a reliable decrement in 5OSA's performance similar to that of other groups. This decrement may have reflected the modification of nonshock aftereffects for $50 \mathrm{SA}$ by successive extinction trials.

\section{Time-dependent learning deficit caused by hydroxylamine}

\author{
STANISLAV REINIS \\ Department of Physiology, Ghana Medical School, Accra, Ghana*
}

The effect of 0.5-M hydroxylamine injected intracranially on a passive-avoidance task was followed in mice. Hydroxylamine administered $24 \mathrm{~h}$ before the acquisition trial or earlier had no effect on performance of animals. Hydroxylamine injected $2 \mathrm{~h}$ before the acquisition trial impaired the performance of animals tested $24,48,72 \mathrm{~h}$, or 1 week later. Hydroxylamine injected 1,2 , or $24 \mathrm{~h}$ later interfered with the performance of animals, too. The later hydroxylamine was injected, the later the impairment of performance of animals appeared. The effect of hydroxylamine is probably associated with the "mutagenic" action of the drug on activated DNA.

In our previous papers (Reinis, $1970 \mathrm{a}, \mathrm{b})$, we described the effect of hydroxylamine on retention of two different learning situations-alimentary conditioning and learned preference to one arm of a water maze. We associate the effect of hydroxylamine on learning with the metabolic disturbances of the affected nerve cells, from which the transcription of changed DNA may be one of the important constituents. Hydroxylamine is bound to several nucleotides of activated derepressed DNA and causes "misreading" of the code. Abnormal proteins are synthetized (Beguin \& Kepes, 1963), which may be responsible for the delayed effect of the drug.

In the present paper we tried to correlate the interval between acquisition trial and hydroxylamine injection with the time of appearance of the behavioral

*Present address: Department of Psychology, York University, 4700 Keele Street, Downsview 463, Ontario, Canada.
RIFERENCES

BL OON. J. M., \& CAPALDI, E. J. The behavior of rats in relation to complex patterns of partial reinforcement. Journal of Comparative \& Physiological Psychology, 1961, 54, 261-265.

IRANCHINA, J. J. Transfer of escape training. Journal of Comparative \& Physiological Psychology, 1968, 65, 175-178.

FRANCHINA, J. J. Intertrial intervals and shock schedules in escape training. Journal of Comparative \& Physiological Psychology, 1969.67, 510-515.
University of Ghana Medical School in Accra. Rat males, weighing $25.30 \mathrm{~g}$ and aged at least 2 months, were used for the experiment. The mice were brought 4.5 days before the experiment into an air-conditioned room $\left(23^{\circ} \mathrm{C}\right)$ and kept in this room up to the end of the experiment.

The apparatus consisted of a covered wooden chamber $28 \times 28 \times 25 \mathrm{~cm}$. A narrow chamber, $16 \times 11 \times 28 \mathrm{~cm}$, made from semitransparent acrylic plastic, was attached to the wooden box. The wooden chamber was provided with a grid floor wired to a power supply that administered a $4.5-\mathrm{mA}, 100-\mathrm{Hz}$ footshock to the animal when it entered it through a $7-\mathrm{cm}$-diam hole connecting the two chambers. The mice were placed into the smaller transparent lighted chamber from which they stepped spontaneously into the bigger dark one. The interval between the placement of the animal into the lighted compartment and its entry through the hole into the darkened chamber (response latency) was measured in this acquisition trial.

The $0.5 . \mathrm{M}$ hydroxylamine hydrochloride, adjusted by sodium hydroxide to $\mathrm{pH} 7.35$, was injected intracranially in the dose of 10 microliters towards each hemisphere. For control injections, 0.5-M saline was used. The mice were slightly narcotized with ether, and the skin of the head was cut in the middle line. A thin injection needle was advanced through the temporal muscle. This prevented leakage of the fluid from the skull.

Groups of animals were injected 2 weeks, 1 week, $72,48,24$, and $2 \mathrm{~h}$ before the acquisition trial and 1,2, 4, and $24 \mathrm{~h}$ after the acquisition trial. Each injection group was split into four test-time groups, the first being tested $24 \mathrm{~h}$, second $48 \mathrm{~h}$, third $72 \mathrm{~h}$, and fourth 1 week after the acquisition trial. Each animal was tested only once. There were 12 animals in each test-time group. The test trial was conducted in essentially the same fashion as the acquisition trial. The latency of entering the dark compartment was measured with a stopwatch. A 300-sec cut-off time was used for the test trial

Table 1

Response Latency in First (Acquisition) Trial in Mice Injected by Hydroxylamine

\begin{tabular}{|c|c|c|c|c|}
\hline \multirow[b]{2}{*}{ Injection } & \multicolumn{2}{|c|}{ Saline } & \multicolumn{2}{|c|}{ Hydroxylamine } \\
\hline & $\begin{array}{c}\text { Number of } \\
\text { Animals }\end{array}$ & $\begin{array}{l}\text { Time in } \\
\text { Seconds }\end{array}$ & $\begin{array}{c}\text { Number of } \\
\text { Animals }\end{array}$ & $\begin{array}{l}\text { Time in } \\
\text { Seconds }\end{array}$ \\
\hline No injection before trial & 360 & & $19.1 \mathrm{sec}$ & \\
\hline 2 weeks before & 24 & 21.1 & 24 & 18.3 \\
\hline 1 week before & 24 & 22.7 & 24 & 16.7 \\
\hline $72 \mathrm{~h}$ before & 48 & 17.8 & 48 & 20.0 \\
\hline $48 \mathrm{~h}$ before & 48 & 15.3 & 48 & 23.0 \\
\hline $24 \mathrm{~h}$ before & 48 & 21.6 & 48 & 25.2 \\
\hline $2 \mathrm{~h}$ before & 48 & 17.4 & 48 & 17.4 \\
\hline
\end{tabular}

